\title{
A two way view of gender bias in medicine
}

\author{
M Teresa Ruiz, Lois $M$ Verbrugge
}

"It isn't true, couldn't be; there must be other variables not taken into account that confound the results. " This was the remark of an incredulous psychiatrist colleague to the statement that there is reasoned evidence of inequalities in health care based on patient gender. His reaction aligns with that of health professionals' and researchers' longing for simplicity in outcomes and also with a contemporary style of data analysis. It is not unusual to hear statements like his when criticisms are voiced about health services for women compared to men.

This editorial comment considers how health care contributes to the health inequalities associated with gender, a question addressed by many since the WHO European Report in 1990. ${ }^{1-6}$ There are two ways in which health service delivery and research can involve gender bias - firstly, by assuming that women's and men's health situations and risks are similar, when in fact they are not, and secondly, by assuming differences where there are actually similarities. Actions and research that follow either approach may influence women's health outcomes in negative ways. An increasing number of scientific papers on gender bias in the past five years has intensified the debate because results often confirm the hypothesised presence of inequity. Yet there remain some conceptual, methodological, and empirical limitations that keep the picture hazy.

\section{The first view: assumed equality of women and men}

Scientists have often assumed that disease risks and expressions are similar or the same in men and women. The many clinical trials that have been conducted only among men carry the assumption that the results can automatically be applied to women, as if women had been studied too..$^{7-9}$ The persistent exclusion of pregnant women from trials (which, of course, is very often important for reasons of safety) may serve to reinforce the assumption of no gender differences, without proof. As a consequence, there is absence of useful knowledge about how to manage women's health problems efficiently and effectively. The practice of excluding women may well jeopardise the health of the group it was intended to protect.

Furthermore, for diseases that are common in both sexes but perceived as being more prevalent in men, the knowledge on which the diagnostic process is based is frequently ob- tained from studies in men, but it is readily applied to women. ${ }^{10}$ Similarly, risk factors and protective factors detected for men are extrapolated directly to women. ${ }^{11}$ Risk factors that are highly relevant in women's lives, such as those due to housework, are not well investigated. ${ }^{3}$ As another example, the relationship between oestrogen therapy and cardiovascular diseases ${ }^{12}$ has been studied far less than the risk factors typical in men's lives.

The Aristotelian concept of human beings argues that they differ from other animals by bringing not just physical nature to their actions, but also culture and reason. ${ }^{13}$ This produces a richer and more complex behavioural repertoire, and it offers great challenge for empirical understanding. The biomedical model that underlies most medical and clinical research does not take into account the influences of reason and culture, the distinctive cognitive and social features of humans. Men and women differ in the ways they think about health problems and in their social behaviour that prompts or avoids health problems. Because of the medical orientation, we know little about how men and women voluntarily adopt some risk behaviours and risk exposures, their different perceptions of symptoms and expression of complaints, how their milieux of social support affect health and health behaviour, and their behavioural strategies for treating and adjusting to health problems.

A statistical reflection of the "sexes-areequal" assumption appears in multivariate analyses of health data. Sex is an included variable, but it serves as a potential confounder rather than a predictive or prognostic variable. No particular substantive interest is given to it. ${ }^{14}$ Its effects are statistically controlled and ignored. ${ }^{4}$

\section{The second view: assumed differences of} women and men

A contrasting view occurs in those situations where women and men are viewed as fundamentally different in respect of health, and yet this is not the case. The notion of intrinsic differences is rooted in historical and scientific discussions that focus on women's reproductive health.

Within this perspective, research showing unequal evaluation of men's and women's complaints by medical doctors should be noted. Physicians often appraise men's complaints as being more serious, and also are more likely to 
assert that there is a psychosomatic component in women's complaints. ${ }^{15}$ High rates of prescribing tranquillisers to women have been cited as a practice that both assumes and creates gender differences. ${ }^{16}$

Health professionals and society at large assume that women enjoy better health status than men. This stems from knowledge of men's higher mortality rates and lower life expectancy. Greater research interest in the diseases that cause high mortality among men reinforces myths that chronic diseases in general are more severe, frequent, and fatal in men. ${ }^{10}$ This perspective completely ignores the fact of the higher prevalence in women of non-fatal chronic conditions which negatively affect their functioning and wellbeing during their adult years, including the "extra" years of life. Women have higher rates of morbidity and disability during life than men do, largely because they accumulate non-fatal conditions more than men do.

\section{The outcome of the two views}

Like a polarised lens, gender bias can arise from two views - one assuming equality where there are genuine differences and the other assuming differences where none may exist. The views originate in a biomedical model that assumes equality for physical health problems and inequality for emotionally-toned ones and self expressed health. Focusing on risk factors prominent in men's lives sidesteps potentially important risks that are prominent in women's lives. In short, a full view of the social factors that underlie disease onset, patient-physician relationships, and health behaviour is needed to find the basis of gender differences. By contrast, a partial view leaves women out or misconstrues their genuine health risks and profiles.

\section{Consequences of gender bias}

There are serious and important consequences of gender bias for women's lifetime health. We discuss three that relate to medical knowledge, clinical management, and health services delivery.

The first consequence stems from incorrect assumptions of no gender difference in disease experience. With most research attention devoted to fatal chronic conditions and the resulting knowledge used to develop medical therapies that influence them, non-fatal chronic conditions are left "as is". A better balance and reorientation of disease-specific research is needed so that conditions that predominate in women, such as arthritis, are given appropriate attention. ${ }^{17}$ Research on non-fatal conditions will ultimately benefit men who, if they live long enough, eventually acquire the same repertoire of non-fatal problems. Recalling the argument that women need to be included in studies of fatal diseases, here we argue that one must be sure men are included in research studies of non-fatal ones!

The second consequence originates in the assumption of no gender difference in disease manifestations. Higher proportions of women than men are assigned diagnoses of "non-specific symptoms and signs" in both health service records and death certificates. ${ }^{18-20}$ It is possible that medical knowledge has been built up over the decades in ways that yield a disease classification more suited to men's complaints, health problems, and signs or symptoms indicative of specific conditions. Patients classified as having non-specific symptoms and signs may indeed suffer an identifiable disease, either at an early stage not captured by contemporary (male-based) diagnostic criteria or by an atypical (non-male) set of complaints for the disease. No treatment or improper treatment at this point can lead to disease worsening, particularly among women.

Thirdly, the assumption of gender differences lies behind differential provision of health services and treatment outcomes. Although primary health care is used more often by women, ${ }^{21}$ data indicate that short-stay and emergency hospital services are more accessible to men. ${ }^{191-23}$ Women wait longer than men in emergency rooms before they are evaluated. ${ }^{224}$ These statistics are routinely explained by saying that men suffer more severe and complicated health problems. Stated otherwise, it is assumed women are healthier but have worse perceptions of their health. But this is countered by scientific studies which show, firstly, that when men and women use emergency services, their hospitalisation rates are equal and, secondly, women admitted to hospital for cardiovascular disease have higher mortality from that cause than men. Such evidence suggests that the initial complaints and presentations are very similar, but that women are delayed in receiving hospital care until their conditions are more severe than men's. Thus, the initial presumptions that men and women differ in symptom perceptions and disease severity may be incorrect but may be very influential in treatment decisions and outcomes.

\section{Research evidence, limitations, and challenges}

A literature review in 1992 on gender bias in medical care ${ }^{25}$ showed few papers published from 1966-91. Three papers in 1974-79 discussed gender differences in mental health and psychological treatment and diagnosis; one in 1983 was on gender aspects of injuries and rehabilitation. From 1986-91, eight papers were published which showed gender bias in access to coronary bypass surgery or angioplasty $(\mathrm{n}=5)$ and access to kidney transplant or dialysis $(n=3)$.

We updated the review using the same bibliographic database (Medline). The pace has quickened, with 21 papers published in journals between 1992 and $1995 . .^{24-45}$ Seventeen deal with gender bias in diagnosis and therapy for cardiovascular diseases. The others are on abdominal aneurysm repair, anti-asthma drugs, orthopaedic surgery for degenerative arthritis, and referral to specialists and access to emergency care (one paper for each topic). This publication growth aligns with rising social and 
scientific interest in gender differences and inequities. Silence is the main enemy of gender inequality, and it seems to be breaking.

The great majority of studies noted above (which our readers may wish to consult) show evidence of gender bias in the health care process. The work has been conducted by social scientists and, more recently, also by medical practitioners concerned about specific diseases. There is little participation in this research by epidemiology and public health researchers. Contributions from these people would improve the statistical methods used and interpretations of secondary data, and also bring new data and thinking to the matter. The current near-monopoly of cardiovascular health problems in the topic would also be altered, with other health problems brought into consideration. (We note that the initial work on gender bias in health care for cardiovascular conditions was applauded, rather than criticised, and this gave researchers confidence to follow the path with further research.)

Conducting research on gender bias faces two limitations. One relates to social attitudes and the other to methodology.

\section{ATTITUDES}

With regard to attitudes, gender bias occurs in health services due to the broader political stratification of society in relation to gender. It is not deliberate; if so, it could be construed as malpractice. It emerges, time and again, via beliefs and interpretations of medical practitioners who believe they are doing the best for their patients. Physicians usually cannot believe gender bias exists, based on their well motivated and well trained clinical practices.

\section{METHODOLOGY}

With respect to methodology, scientific discussions of gender bias tend to fall into two camps - it exists, or it does not. The truth is certainly diverse; gender bias does exist in some arenas and does not in others. Moreover, the fact that one study finds gender bias in a specific medical procedure, but another study fails to replicate the results or finds no bias in a related procedure, is not a sign of bad science and zero knowledge. Characterising gender bias will require detailed research in which variables are identified that specify its occurrence and its absence. Severity is a crucial variable to measure in this research, as well as some health aspects (symptoms, complaints) that are not typical. The result will be knowledge through which specific interventions can be designed to reduce the negative consequences of gender bias on women's health. Epidemiology and other public health disciplines are well suited to research using this perspective.

We note also that the importance of gender bias rests not so much in the strength of associations (relative risks) as in the size of the population exposed to identified risks (women). Even if the chances of gender bias are quite low in some health circumstances and health care settings, those risks are experienced by a large population group.

\section{CHALLENGES}

Several challenges in relation to gender bias lie ahead.

- Firstly, democratisation in the production of knowledge must be improved; health problems experienced by both men and women should be studied with samples including both.

- Secondly, research designs should take both differences in male/female nature and in men's/women's roles into account in the search for predictors of health problems and outcomes.

- Thirdly, careful consideration of gender bias in disease classifications should be made. In addition, research oriented by complaints and symptoms will help reveal how women and men with similar problems end up with dissimilar diagnoses.

- Fourthly, gender should always be a substantive variable rather than a control variable in health research

- Finally, innovative designs are needed to uncover the precise features of patient presentation or physician attitude that lead to inequalities in access and outcome for men and women.

The growing evidence of gender bias in health services can generate defensive postures because it belies the beliefs and cherished values of many health professionals. High chances of conflict and dissent should not dissuade researchers from studying gender bias. Results which are uncomfortable for readers can lead to more tailored research questions that get still closer to finding the specific circumstances where bias does and does not occur. Only by widening the empirical net on this issue can bias in particular clinical settings be detected, noted, and eventually avoided.

After listening to the arguments above, the psychiatrist commented that when he or his colleagues receive a phone call from the emergency room requesting psychiatric attention for a person who has attempted suicide, they routinely ask what the patient's sex is. They hurry more if it's a man. He wondered if this happened in other hospitals, or specialties, or countries. And then we agreed that this is an excellent hypothesis for scientific study.

1 Whitehead M. The concepts and principles of equity and health Copenhagen: WHO Regional Office for Europe, 1990.

2 Krieger N, Rowley DL, Herman AA. Racism, sexism, and social class: Implications for studies of health, disease, and well-being. Am F Prev Med 1993;9(suppl 2):82-122. 3 Oakley A. Who cares for health? Social relations, gender, and public health. F Epidemiol Community Health 1994 48:427-34.

4 Stephenson P, McKee M. Look twice. Eur f Public Health 1993;3:151-2.

Angell M. Caring for women's health - What is the problem? N Engl f Med 1993;329:271-2.

6 Mont-Girbau JL. Tratamiento de la cardiopatía isquémica en mujeres: existe discriminación en función del sexo? (Editorial). Med Clin (Barc) 1994;102:374-5.

Bennett JC. Inclusion of women in clinical trials. Policies for population subgroups. N Engl f Med 1993;329:288-92. for population subgroups. N En lypolation from data on 8 Cotton P. Is there still too much ical news and perspectives. mAMA 1990;263(8):1049-50. 
9 Schmucker DL, O'Mahony MS, Vesell ES. Women in clinical trials. An update. Clin Pharmacokinetic 1994;27(6): 411-7.

10 Healy B. The Yentl syndrome. $N$ Engl $\mathcal{F}$ Med 1991;325: 274-5.

11 Manson JE, Stampfer MJ, Colditz GA, Willett WC, Rosner $B$, Speizer FE, Hennekens $\mathrm{CH}$. A prospective study of aspirin use and primary prevention of cardiovascular disease in women. $¥ A M A$ 1991;266:521-7.

12 Stampfer MJ, Colditz GA, Willett WC, Manson JE, Rosner B, Speizer FE, Hennekens CH. Postmenopausal estrogen therapy and cardiovascular disease. N Engl f Med 1991; 325:756-62.

13 Bambrough R. The philosophy of Aristotle. New York: Mentor Books, 1963:382-5.

14 Ganz PA. Age and gender as factors in cancer therapy. Clin Geriatr Med 1993;9:145-55.

15 Colameco S, Becker LA, Simpson M. Sex bias in the assessment of patients complaints. F Fam Pract 1983;16: 1117-21.

16 Ashton H. Psychotropic-drug prescribing for women. $\mathrm{Br} \mathcal{F}$ Psychiatry 1991;10(suppl):30-5.

17 Verbrugge LM. Women, men, and osteoarthritis. Arthritis Care and Research 1995;8:212-20.

18 Hibbard JJ, Pope CR. Another look at the sex differences in the use of medical care: Illness orientation and the types of morbidities for which services are used. Women and Health 1986;11:21-36.

19 Ronda E, Ruiz MT, Alvarez-Dardet C, Martí C. Gender bias in diagnostic procedures at the primary health care bias in diagnostic procedures at Public Health Association Annual Meeting. Debrecen: Piremon, 1995:61.

20 Mingot M, Borrás JM. Mortalidad diferencial según el sexo en Cataluña. Gac Sanit 1992;28:8-12.

21 van de Waals FW. Differences in leading causes of death, hospitalization and general practice visits among Dutch women and men. Women and Health 1991;17:101-23.

22 Ruiz MT, Ronda E, Alvarez-Dardet C. Atención según el género del paciente en los servicios de urgencias: ¿Diferente o Desigual? Gac Sanit 1995;9:76-83.

23 Anson O, Carmel S, Mordechai L. Gender differences in the utilization of emergency department services. Women and Health 1991;17:91-104.

24 Heston TF, Lewis LM. Gender bias in the evaluation and management of acute nontraumatic chest pain. Fam Pract Res F 1992;12:383-9.

25 Dreachslin J. Gender bias and the process of care. fournal of Management in Medicine 1992;6:46-52.

26 Wenger $\mathrm{K}$. Cardiovascular health and disease in woman. $N$ Engl f Med 1993;329:247-55.

27 Foster DA, Gillette MK, Collins AM. Is there sex bias in the management of coronary artery disease? $N \mathrm{Engl} f \mathrm{Med}$ 1992;326:370-1.

28 Bourassa MG, Gurne O, Bangdiwala SI, et al. Natural history and patterns of current practice in heart failure. $\mathcal{F}$ Am Coll Cardiol 1993;22(4 suppl A):14A-19A.
29 Cassidy TP, Lewis S, Gray CS. Computerised tomography and stroke. Scot Med f 1993;38:136-8.

30 Pagley PR, Yarzebski J, Goldberg R, et al. Gender differences in the treatment of patients with acute myocardial infarction. A multihospital, community-based perspective. Arch Intern Med 1993;153:625-9.

31 Chiriboga DE, Yarzebski J, Goldberg RJ, et al. A communitywide perspective of gender differences and temporal trends wide perspect in the use of diagnostic and revascularization procedures for acute

32 Latour J. Esfuerzo terapéutico al ingreso en mujeres con infarto agudo de miocardio. Med Clin (Barc) 1994;102: 361-3.

33 Hildon A. Gender bias in cardiology: are women missing out on PTCA? Australian fournal of Advances in Nursing 1994;12:6-11.

34 Gregor RD, Bata IR, Eastwood BJ, et al. Gender differences in the presentation, treatment and short-term mortality of acute chest pain. Clin Invest Med 1994;17:551-62.

35 Johnston KW. Influence of sex on the results of abdominal aortic aneurysm repair. $\mathcal{f}$ Vasc Surg 1994;20:914-23.

36 Hutchinson LA, Pasternack PF, Baumann FG, Grossi EA, Riles TS. Is there detrimental gender bias in preoperative gery? Circulation 1994;90(5(2)):220-3.

37 Tsuyuki RT, Teo KK, Ikuta RM, Bay KS, Greenwood PV, Montague TJ. Mortality risk and patterns of practice in Montague TJ. Mortality risk and patterns of practice in 2,070 patients with acute myocardial infarction, 1987-92. Relative importance of age

38 Roberts SJ, Bateman DN. Which patients are prescribed inhaled anti-asthma drugs? Thorax 1994;49:1090-5.

39 Jaglal SB, Goel V, Naylor CD. Sex differences in the use of invasive coronary procedures in Ontario. Can $\mathcal{f}$ Cardiol 1994;10:239-44.

40 Bearden D, Allman R, McDonald R, Miller S, Pressel S, Petrovitch $H$. Age, race, and gender variation in the utilization of coronary artery bypass surgery and angioplasty in systolic hypertension in the elderly program. gioplasty in systolic hypertens

41 Mark DB, Shaw LK, DeLong ER, Califf R, Pryor DB. Absence of sex bias in the referral of patients for cardiac catheterization. N Engl ₹ Med 1994;330:1100-6.

42 Katz J, Wright E, Guadagnoli E, Liang M, Karlson E, Clearly P. Differences between major orthopaedic surgery Clearly P. Differences between major orthopaedic surgery

43 McGann KP, Marion GS, Szewczyk MB, Davis SW. Absence of sex differences in the evaluation of patients hospitalized for transient ischemic attacks. 7 Fam Pract 1994;39:134-9.

44 Vacek JL, Handlin LR, Rosamond TL, Beauchamp G. Gender related differences in reperfusion treatment allocation and outcome for acute myocardial infarction. $A m$ f Cardiol 1995;76:226-9.

45 Bell MR, Berger PB, Holmes DR, Mullany CJ, Bailey KR, Gersh BJ. Referral for coronary artery revascularization procedures after diagnostic coronary angiography: evidences for gender bias? $7 \mathrm{Am}$ Coll Cardiol 1995;25:1650-5. 